\title{
Environmental and Health Safety Considerations of Nanotechnology: Nano Safety
}

\author{
Eman M Osman* \\ Textile Metrology Department, Chemical Metrology Division, National Institute of Standards, Egypt
}

*Corresponding author: Eman M Osman, Textile Metrology Department, Chemical Metrology Division, National Institute of

Standards, Egypt

ARTICLE INFO

Received: 幽 July 05, 2019

Published: July 17, 2019

Citation: Eman M Osman. Environmental and Health Safety Considerations of Nanotechnology: Nano Safety. Biomed J Sci \& Tech Res 19(4)-2019. BJSTR. MS.ID.003346.

\begin{abstract}
Nanotechnologies are being spoken of as the driving force behind the new industrial revolution. The mass production of these nano materials and their applications mean a dramatic increase of workers dealing with Engineered Nano Materials ENM and becoming possibly exposed to resulting hazardous effects and increased environmental burden of the environment due to the leaks of these materials from industrial processes. It is hence essential to consider the importance of ENM safety and their new applications and understand that, it is important for these materials and products to be safe to enable successful promotion of nanotechnology for useful applications. The aim of this article is to review the impact of the ENM on both human and environment. Also, the risk and the risk assessment of the ENM we deal with.
\end{abstract}

Keywords: Engineered Nanomaterials; Hazard Assessment; Risk Assessment; Environmental Impact; Health Impact; Control Measures

\section{Introduction}

The term nanotechnology describes a range of technologies performed on a nanometer scale with widespread applications including the production and application of physical, chemical, and biological systems at scales ranging from individual atoms or molecules to around 100 nanometers. A nanometer is one billionth of a meter, which is near-atomic scale [1-2]. Nanotechnology is an empowering innovation that can possibly bring advantages to different zones of research and applications and to improve our lives in numerous ways. Right now, the Engineered Nano Materials (ENM) , for example deliberately made nanomaterials, invaded practically all the modern parts incorporating those related with, data advances, gadgets, energy generation and storage, material sciences, sustenance, environmental remediation, security, transport furthermore, space, indicative and restorative applications in drug [3]. Thus, it isn't astounding that nanotechnology industry is relied upon to develop amazingly before the finish of 2020. Some have portrayed nanotechnology as a two-edged sword.

On one hand, some are worried about that, the nanoscale particles may enter and gather in crucial organs, for example, the lungs and cerebrums, possibly making mischief or demise people furthermore, creatures, and that the dispersion of nanoscale particles in the earth may hurt environments [4]. Then again, some trust that nanotechnology has the potential to convey significant Environmental, Health And Safety (EHS) advantages, for example, decreasing vitality utilization, contamination, and ozone harming substance discharges; remediating ecological harm; relieving, overseeing, or forestalling illnesses; and offering new safety enhancing materials that are more stronger, self-repairing, and ready to adapt to give protection [5]. Nanotoxicology is the field which concentrates potential health dangers of nanomaterials. The amazingly little size of nanomaterials implies that they are substantially more promptly taken up by the human body than bigger estimated particles.

The conduct of nanoparticles inside the living being is a component of their size, shape and surface reactivity with the surrounding tissue. In the event that non-degradable or gradually degradable nanoparticles gather in organs, a potential connection with natural procedures inside the body will happen because of their enormous surface area to volume ratio. On exposure nanoparticles to tissue and liquids they will promptly adsorb onto their surface a portion of the macromolecules they encounter. The enormous number of factors affecting poisonous quality implies that, it is hard to make speculations regarding health risks related with exposure to nanomaterials - each new nanomaterial must be evaluated separately, 
and every single material property must be considered. Health and environmental issues must be taken in thought when managing the working environment of either organizations occupied with creating nanomaterials or the labs occupied with nanoscience and nanotechnology explore Laborers who use nanotechnology in research or generation procedures might be uncovered to nano materials through inward breath, skin contact, or ingestion.

Also, the surrounding environment might be helpless to genuine impacts because of spillage of nanoparticles coming about because of production, handling, storing and even disposal. This survey gives fundamental data on the most present dubious issues concerning the comprehension of potential risks related with this quickly creating innovation and features measures to control exposure to nano materials in the working environment.

\section{Sources of Nanoparticles}

Nano particles are not a new phenomenon since they could be occurred: naturally, incidentally or intentionally, as seen below [67]:

\section{Normally happening Nanoparticles}

Numerous sorts of nanoparticles happen normally in matter or in the environment. Numerous organic materials, found in human food or food ingredients, are normally nanostructured or contain nanoparticles. Casein micelles can be considered as nanoparticles. They are the real protein segment of milk and in charge of conveying mineral supplements, for example, calcium and phosphate to neonates. It is well investigated the nearness of nanoparticles in the climate where their focus and arrangement are exceptionally factor from place to another. Common emissions from trees and different plants or soil volatiles just as from soil disintegration can dominate in certain areas, while particles from ocean splash may dominate somewhere else. Likewise, volcanic ash may convey enormous amounts of natural nanoparticles into the environment.

\section{Unexpectedly Occurring Nanoparticles}

Another type of atmospheric nanoparticles are the accidental results of procedures including industrials, burning, welding, and transportation activities.

\section{Intentionally Occurring Nanoparticles}

The well-known nanoparticles are the intentionally man-made or the engineered nanoparticles which can be made in the labs, for example nano particles of metals, metal oxides, metal hydroxides, or even polymers. These designed nanoparticles can be utilized in several fields; either industrial or therapeutic. Figure 1 speaks to rundown of the majority of the nanoparticle's resources in our every- day life [8]. The nearby centralizations of nanoparticles in the atmosphere are significantly influenced by environmental conditions and depend firmly on emission intensities, vicinity to sources, and meteorological conditions. All in all, the highest number of concentrations happens in urban zones while regular sources dominate in rural regions [9]. Environmental and Health safety (EHS) concerns have concentrated principally on nanoscale materials that are deliberately structured and delivered frequently alluded to as Engineered Nanomaterials (ENM). Figure 2 condenses the environmental abundance of nanoparticles as an element of environment.

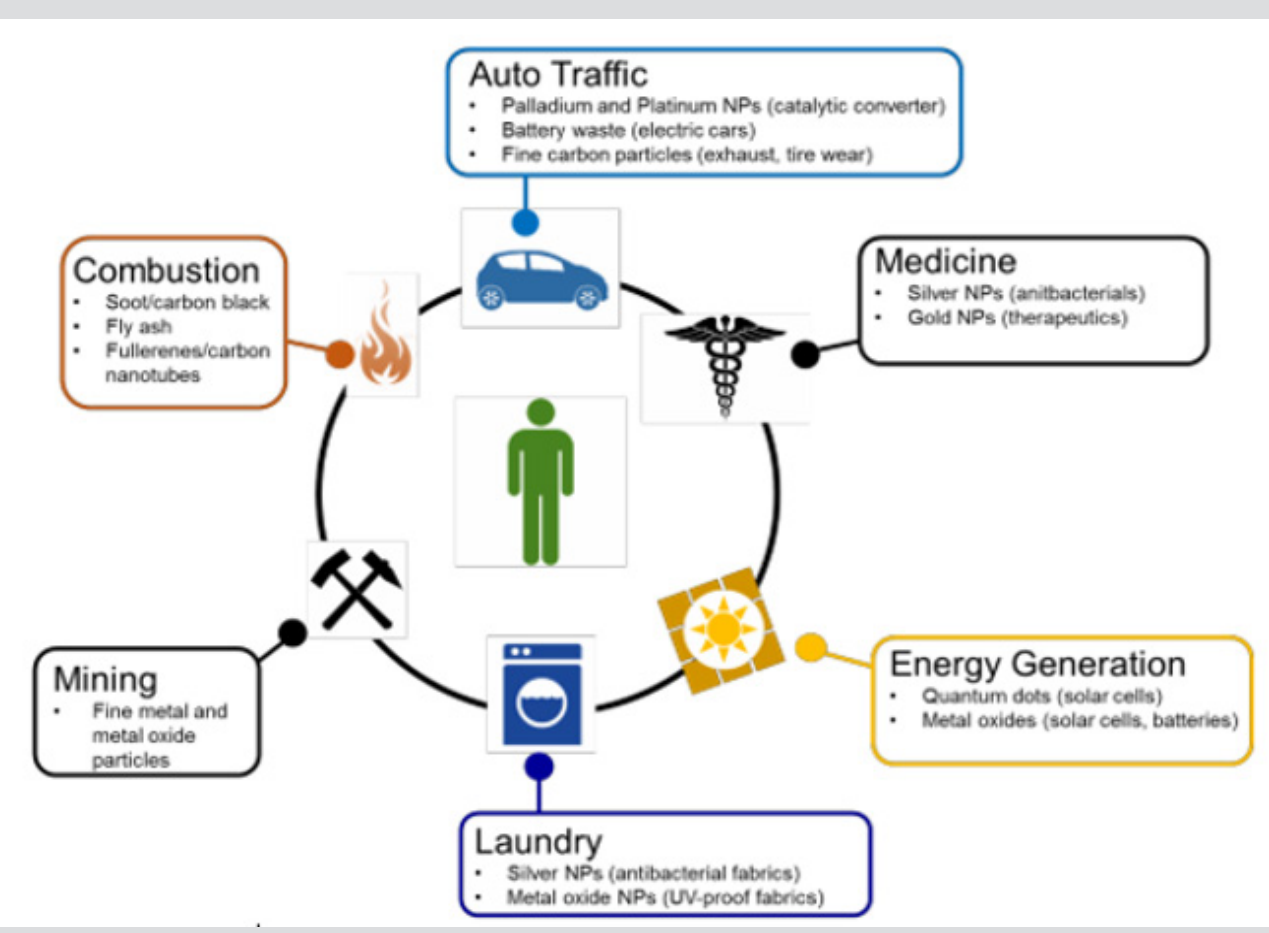

Figure 1: Sources of nanoparticles in daily life. 


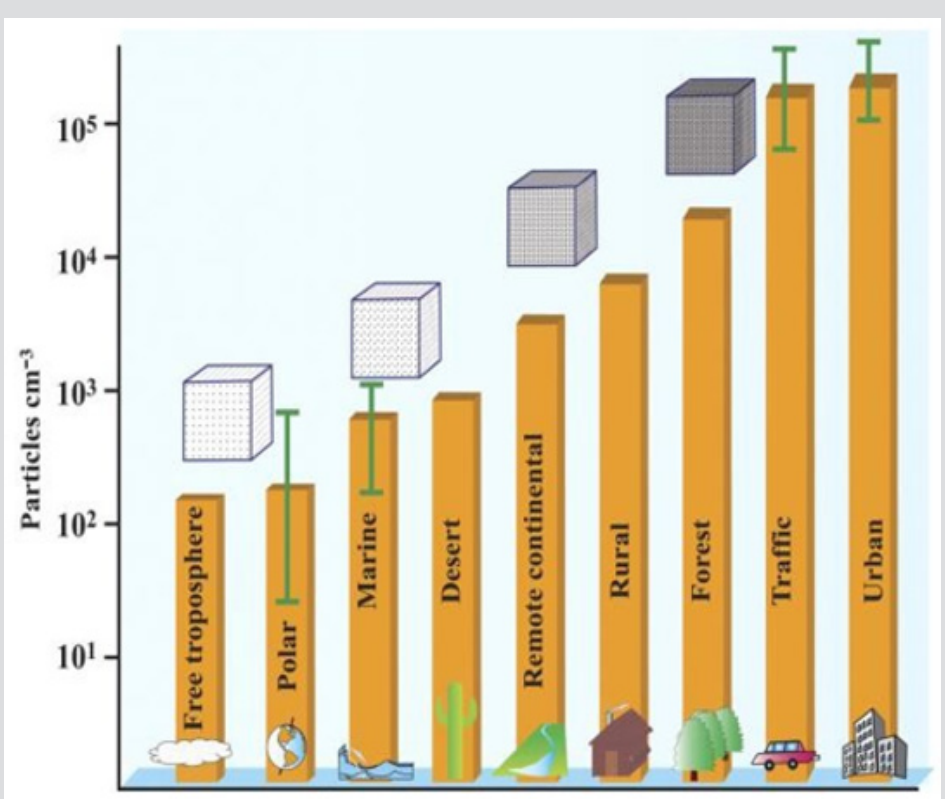

Figure 2: Concentrations (particles $/ \mathrm{cm}^{3}$ ) of nanoparticles in the atmosphere in various environments

\section{Application of Nanotechnology in the Textile Industry}

Textile ecology points not to hurt environment and individuals in all phases of the material generation from fabric production to production of garments. By and by, materials and synthetic compounds utilized for creation of fabrics cause weakening of environmental balance. Synthetic compounds utilized in material items may make a health hazard [10].

Nanotechnology can possibly be connected over the whole pipeline of the improvement of materials. The key points of applying nanotechnologies inside the materials sector are to:

a) Update present capacities and execution of textile materials, and b) Create inventive items, specifically smart/functional materials with new highlights and functions (for example stainproof, self-cleaning, conductive, and so on).

Mantovani and Zappelli [11] researched the potential applications for nanomaterials crosswise over four key sub-areas of the textile production: nanomaterials and nano composites; fiber creation (ex. electrospinning); completing medicines; and nano-related material items. A range of nanomaterial types are connected inside the material area, with the most regularly utilized being carbon nano tubes CNTs, zinc oxide, silver, titanium dioxide-nanoparticles. Figure 3 speaks to the various utilizations of nanotechnology in textile products.

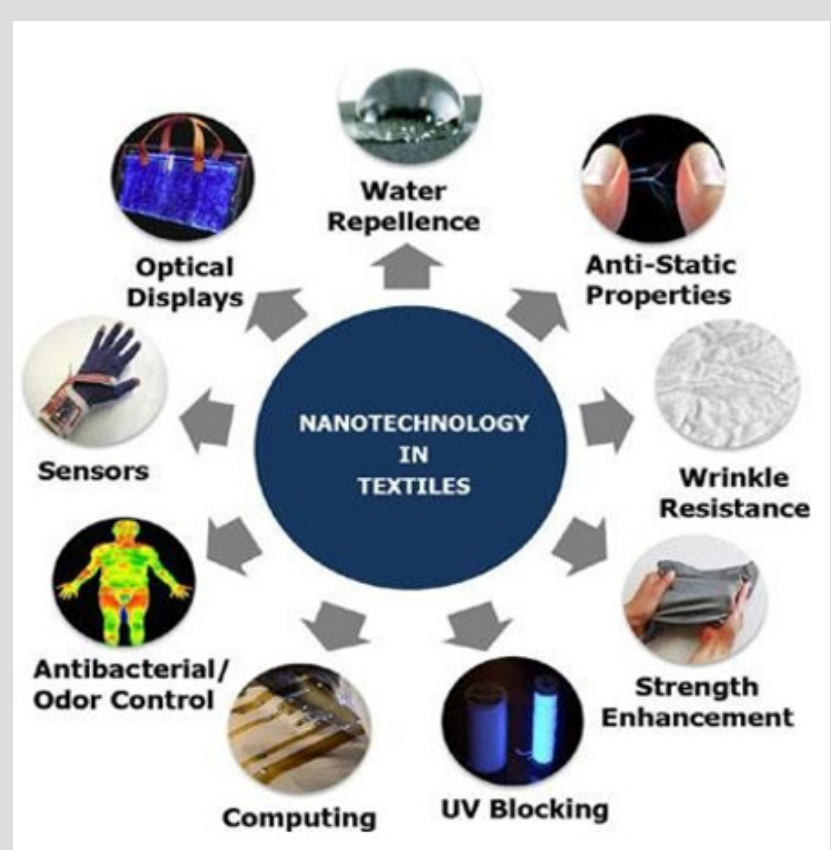

Figure 3: Applications of nanotechnology in textiles. 


\section{Hazards of Nano Engineered Materials}

The presence of nanomaterials isn't in itself a risk. It is just certain perspective that can make them dangerous, specifically, their versatility and their expanded reactivity. Just if certain properties of certain nanoparticles were harmful to living creatures or the environment, for this situation, it tends to be called nano pollution [12].

Regarding to the health and environmental impact of nanomaterials we have to separate between two sorts of nanostructures:

a) Fixed nano-particles: where nanoscale particles are consolidated into a substance, material or device (electronic, optical, sensors and so on.); and

b) Free nanoparticles: where individual nanoparticles of a substance are available at some phase in production or use.

There is by all accounts accord that, albeit one ought to know about materials containing fixed nanoparticles, the quick concern is with free nanoparticles. In discussing nanoparticles, it is significant that, the phase containing nanoparticles (powder or fluid) never be mono disperse, however contains a range of molecule sizes. This entangles the test investigation, as bigger nanoparticles may have various properties from littler ones. Moreover, nanoparticles demonstrate an inclination to aggregate, and such aggregates regularly act uniquely in contrast to individual nanoparticles.

\section{Safety Considerations}

NANO-SAFETY is definitely not a basic arrangement or a convenient solution, however there should be an orderly methodology that assesses the risks and propose sensible activities to guarantee the security of the two individuals and the environment. New technologies can possibly get benefits just as inconveniences of the exposure of people to new materials. There are three fundamental settings for thinking about safety:

a) Environmental pollution,

b) Unintentional human introduction (exposure in the working environment) and

c) Deliberate human exposure (the intended applications). The exposure of populaces in the working environment and customers and of the environment to nano materials is probably going to rise significantly [13].

In spite of the fact that, there is as of now significant learning on the effect of those environmental nano particles created unintentionally (for example through combustion), on human health basically intervened through respiratory pathways, there are still need in the fitting risk appraisal technique to assess the safety of Engineered Nano Materials. Just the same as each other new technology, Research and Development (R\&D) of nano material items should be joined by safety assessment, including risk assessment and risk-management. Risk assessment and risk management require intelligent and case-explicit thought guided by potential exposure situations [14].

\section{The Impact of Nanotechnology}

Nanotechnology is getting to be boundless in consumer products. As its utilization proceeds to develop, so do worries about its effect on the two people and the environment. The effect of nanotechnology stretches out from its restorative, moral, mental, legitimate and environmental applications, to fields, for example, engineering, biology, chemistry, computing, materials science, and communications.

\section{Health Impact}

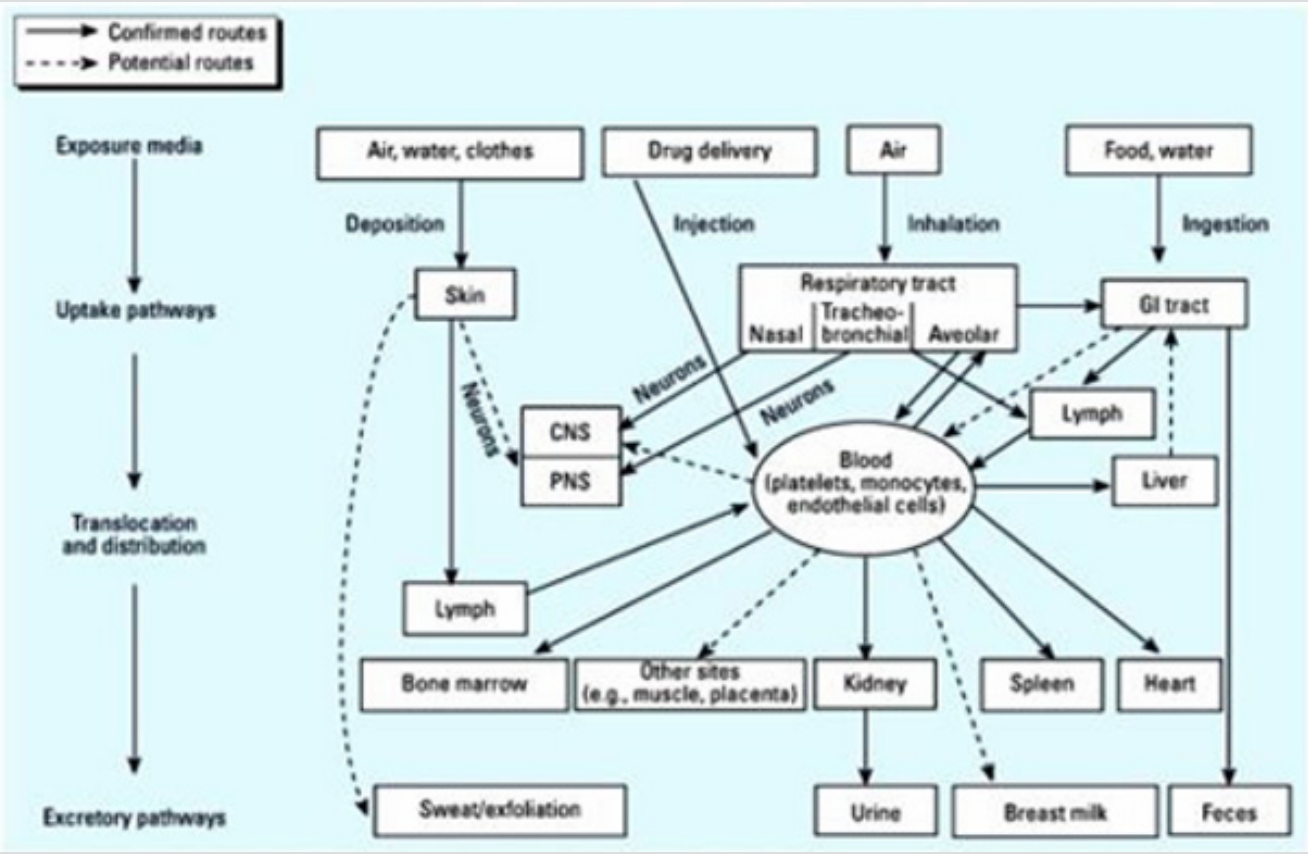

Figure 4: Biokinetics of (Manufactured Particulate Nanomaterials) MPNs. 
The US National Institute for Occupational Safety and Health (NIOSH) has directed starting exploration on how nanoparticles react with the body's systems and how workers may be exposed to nano-sized particles in the assembling or mechanical utilization of nanomaterials. There are three entryways of section for nanoparticles in the human body: the skin, the gastro-intestinal tract and the lung in spite of the fact that, obviously, these entries can be evaded by direct injection or implantation of a substance. Inside the body, there is a high likelihood that nanoparticles will come into contact with immune cells, which can lead to nanoparticle immune system interaction causing inflammation, expanded susceptibility to infectious diseases, or even to immune system diseases or cancer [15]. Figure 4 demonstrates the potential ways that may the nanoparticles go through inside human body [16].

Data from Research and Animal Studies on Nanomaterials Has Recognized Some Potential Safety Risks and Health Impacts, for Instance: Carbon nanotubes: can cause an asbestos-like impact after a low dose and multi week follow-up [17]. Besides, carbon nanotubes and nano fibers might be fit for causing pneumonic inflammation and fibrosis [18].

Titanium Dioxide $\left(\mathrm{TiO}_{2}\right)$ : Some experimental studies conducted by NIOSH [19-20] has determined that, nanoscale $\mathrm{TiO}_{2}$ particles have induced pulmonary fibrosis as well as granuloma formation. Another study revealed that $\mathrm{TiO}_{2}$ nanoparticles could be slightly genotoxic, i.e. affecting DNA [21].

Iron oxide (Fe0): have been appeared to debilitate the microcirculation in different organs [22], and to irritate both heart capacities and influences synapses of the cardiovascular system [23].

Manganese Oxide (MnO): nanoparticles have been exhibited to enter the olfactory bulb through the nose and can be transported to different regions in the mind after inward breath.

Silver Nanoparticles (Ag): covered with polyvinyl-pyrrolidine can evoke dose dependent DNA-damage in vitro [24]. In addition, utilizing silver nanoparticles in wound dressings, advances healing while at the same time decreasing potential contaminations. But these same nanoparticles could likewise destroy helpful bacteria in nature. In this way, the Environmental Protection Agency (EPA) has put limitations on any use of silver nano particles due to its apparent capability in destroying great microscopic organisms whenever discharged into environment [25].

Zinc oxide (ZnO): There is a study which uncovered that, when sun block creams containing a characteristic isotope of zinc oxide were in contact with human skin, the isotope could be dependably estimated in both blood and urine [26-27].

The health hazard potential relies upon the specific nanomaterial and an individual's exposure level [28]. Occupational Safety and Health Administration (OSHA) suggested that:

a) Exposure to respirable carbon nanotubes and carbon nanofibers do not surpass $1.0 \mu \mathrm{g} / \mathrm{m}^{3}$ as a 8-hour time-weighted normal, in view of the National Institute for Occupational Safety and Health (NIOSH) proposed Recommended Exposure Limits [29].

b) Exposure to nanoscale particles of $\mathrm{TiO}_{2}$ mustn't surpass $0.3 \mathrm{mg} / \mathrm{m}^{3}$. While, as far as possible for fine-sized $\mathrm{TiO}_{2}$ (molecule estimate more than $100 \mathrm{~nm}$ ) is $2.4 \mathrm{mg} / \mathrm{m}^{3}$ [30].

At the National Personal Protective Technology Laboratory of NIOSH, studies found that, the most entering molecule size range was somewhere in the range of 30 and $100 \mathrm{~nm}$, and release size was the biggest factor in the quantity of nanoparticles found inside the respirators of the test dummies.

\section{Environmental Impact}

The environmental effect of nanotechnology is the potential impacts that the utilization of nano innovative materials and gadgets will have on the environment. As nanotechnology is a rising field, there is discussion with respect to what degree industrial and commercial use of nanomaterials will influence living beings and biological systems. Although some data is accessible concerning the destinies and impacts of certain classes of nanomaterials in the environment, extra data on word related to occupational consumer and environmental exposure is required [31-32]. Nanotechnology's environmental effect can be part into two perspectives: the potential for nano technological innovations to help in improving nature, and the conceivably novel kind of pollution that nano innovative materials may cause whenever discharged into the environment. Such as in case of silver nano particles that destroy the useful bacteria when released into the environment

\section{Green Nanotechnology}

Green nanotechnology refers to the utilization of either nanotechnology or the results of nanotechnology to improve the environmental maintainability of procedures delivering negative externalities. Green nanotechnology has been additionally described as the development of clean technologies, to minimize potential environmental and human health risks related with the assembling and utilization of nanotechnology items, and to encourage replacement of existing items with new nano-items that are all the more environmentally friendly all through their lifecycle [33]. Green nanotechnology has two objectives: delivering nanomaterials and items without harming environment or human health and delivering nano-products that provide solution to environmental problems. It uses existing standards of green science also, green designing to make nanomaterials and nano-items without toxic ingredients, at low temperatures utilizing less energy and renewable information sources any place as possible, and utilizing lifecycle thinking in all plan and designing stages [34].

\section{Pollution}

Nano pollution is a nonexclusive name for all waste created by nano devices or during the nanomaterials assembling process. 
Nano waste is predominantly the gathering of particles that are discharged into the environment (air and water), or the particles that are discarded when still on their items causing disturbance of the ecosystem, as there is evidence for that MPNs are passing through the food chain from smaller to larger organisms. Since MPNs have been demonstrated to be competent to hurt organisms, it is talked about that, they can affect the functional ecosystem which is subjected to micro flora. All examined groups of manufactured nanoparticles have demonstrated to be toxic to aquatic living beings, for example, zebra fish, daphnia, algae, invertebrates and rainbow trout [35].

\section{Social Impact}

Beyond the toxicity dangers to human health and environment which are associated with original nanomaterials, nanotechnology has more extensive societal impact and postures more extensive social difficulties. Numerous social researchers and associations in common society recommend that, innovation evaluation and administration ought to likewise include public cooperation. Nanotechnologies may give new answers for a huge number of individuals in developing nations who need access to fundamental services, such as , safe water, reliable energy, medicinal services, and education. The impacts of nanotechnology on: society all in all, human health and environment, the trade, security, food systems and even on the meaning of "human", have not been portrayed or politicized at this point [36].

\section{Hazard Assessment}

Despite the fact that, there are many research ventures overall evaluating the potential hazards and dangers, there have been worries about their quality and significance. The absence of institutionalized materials and methodologies makes it hard to analyze results from various analysts and diverse nano products. Past the lung, there are numerous gaps in learning about the health impacts that may happen after inhalation, in connection to take-up, distribution, accumulation and biological impacts in secondary organs, in spite of the fact that it is known, for instance, that some nano particles can cross the blood-brain barrier. Generally, it may be said that, similar properties that are attractive in certain applications are likewise the properties that may offer ascent to toxicity (nano materials paradox). There are a few issues deciding the hazard assessment of nanoparticles, as following:

a) Dose - must be measured dependent on the physicochemical properties of the nano material, over the long term or short term with high dosages.

b) Standardization - it is basically imperative to utilize approved, institutionalized measures so that:

i. Results from various analysts can be thought about, and

ii. Assays in vitro or creature studies can sensibly be relied upon to anticipate an impact in people. c) Studies at the cellular level - there is still little knowledge about how nano particles interact with the cell layer, how they are transported into cells, into lysosomes, mitochondria and the nucleus, and the results of these interactions

d) Studies at organ and system levels - among the needs there is a must to consider toxico-kinetics studies for additional pneumonic translocation and transport after different routes of entry, especially for effect on cardiovascular, nervous, hepatic, immune and endocrine systems. It is similarly critical to do much more in assessing exposure whether intended or unintended. Few studies depicted work environment, consumer or environmental exposure or related exposure to genuine conditions. More investigations should be done to evaluate inhalation exposure in occupational settings and to increase awareness in other different settings [37].

Another vital issue in performing hazard identification proof is the information of the biokinetics of specific manufactured particulate nanomaterials MPN. In this way one compiles the so-called ADME-profile which represents Absorption, Distribution, Metabolism, and Excretion, depicting the mien of the nanomaterials inside the living being [38].

\section{Risk assessment}

Risk assessment is a procedure wherein the probability of a harmful impact to people or populaces is measured. It is often expressed as the formula:

\section{Hazard $x$ Exposure $=$ Risk}

In this way, the hazard is characterized by two attributes:

a) The hazard of the material that should be characterized and identified and

b) The contact with the hazardous material which is the exposure.

For nanomaterials, an appropriate risk assessment is fairly difficult since hazard and exposure appraisals is as yet not clear [39]. Potential risks incorporate environmental, health, and safety issues; have progressed toward becoming prevailing, which are of worry to security rights advocates. These might be especially significant if potential negative impacts of nanoparticles are neglected. Regulatory bodies, for example, the United States Environmental Protection Agency and the Health and Consumer Protection Directorate of the European Commission have begun managing the potential risks of nanoparticles [40]. There are two kinds of potential exposures exist:

a) Chronic: Continuous exposure happens over longer timeframes, ranging from months to years. Concentrations of breathed in lethal contaminants are moderately low. Direct skin contact by submersion, sprinkle, or by defiled air displaying low dermal activity. 
b) Acute: Exposures happen for moderately brief time periods, ranging from minutes to 1-2 days. Concentrations of lethal air contaminants are high. Besides the inward breath, airborne substances may legitimately contact the skin, or fluids and sludge might be sprinkled on the skin or into the eyes, prompting harmful impacts. Most human or ecological medical issues can be assessed by dismembering the analysis into four sections:

i. Problem identification,

ii. Exposure assessment

iii. Dose-response assessment, and

\section{iv. Risk characterization}

This four-stage structure has been broadly received by U.S government/state offices and universal associations that asses and oversee health and environmental issues (see Figure 5) [41]. Most, if not all, accidents in the work environment and occupational diseases are preventable by improving risk management. Now and again with better information and structure, here and there by better principles and requirement, in some cases with better accessibility of human abilities to confront unfavorable workplace or to keep running in front of occasions.

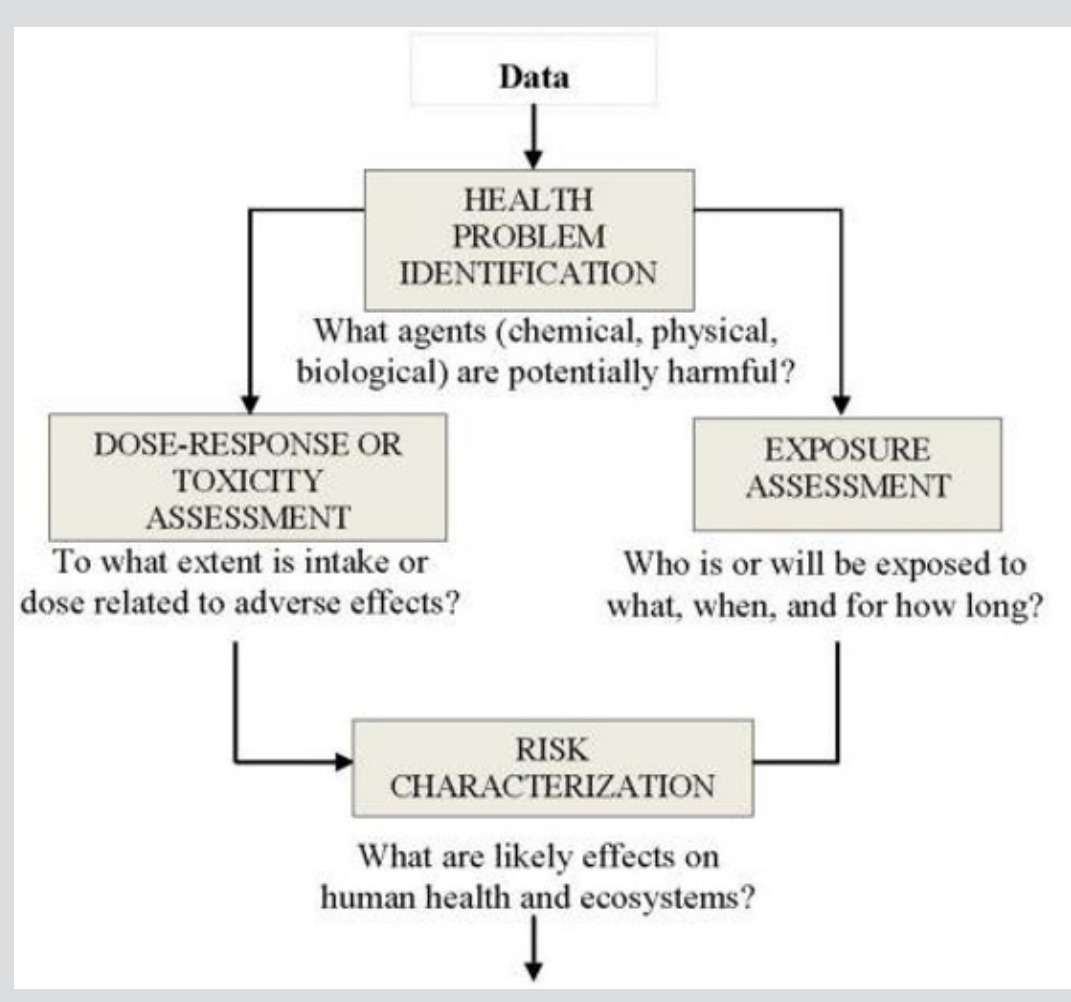

Figure 5: The Health Risk Evaluation Flowchart.

\section{Measures used to Control Potential Exposure to Nano}

\section{Materials}

Since the exploration and utilization of nanomaterials keeps on extending and data about potential health impacts and exposure limits for these nanomaterials is as yet being created, managers ought to apply a mix of various measures to control potential exposures. As per NOISH, there are a few controls should be possible to catch the airborne nano particles:

\section{Engineering Controls}

a) Exhaust ventilation systems with a high-efficiency particulate air (HEPA) channel ought to successfully use to evacuate nanomaterials [42-43].

b) Where operations can't be enclosed, give neighborhood exhaust ventilation (e.g., catch hood, encasing hood) furnished with
HEPA filters and intended to catch the contaminant at the purpose of age or discharge.

\section{Administrative Controls}

a) The utilization of good cleanliness practices could be empowered by giving hand washing facilities and other related facilities.

b) Establish strategies to address cleanup of nanomaterial spills and sterilization of surfaces to minimize worker exposure. For instance, prohibit dry clearing or utilization of compacted air for cleanup of tidies containing nanomaterials, utilize wet cleaning and vacuum cleaners outfitted with HEPA filters instead.

c) Good work practices (e.g., washing hands, and no eating/ drinking in work territory) can limit worker exposure to nanoparticles [44]. 


\section{Personal Protective Equipment (PPE)}

a) Provide specialists with fitting individual protective types of equipment, for example, respirators, gloves and defensive garments [45].

\section{Medical Screening and Surveillance}

a) Make accessible medicinal screening and surveillance for specialists exposed to nano materials, if suitable [46].

b) Review medicinal surveillance prerequisites under OSHA measures (e.g., Cadmium, Respiratory Protection) [47].

\section{Storage and Disposal Procedures of Nanomaterials}

Nanomaterials are significant for both the general population included and the effect on nature. However, with no information of the essential properties, the degree of the precautionary measures required is obscure. To comprehend the potential effect that any nanomaterial will have on the environment, it is important to indorse the lifecycle point of view. This includes surveying impacts that may happen all through an item's life, including the production, circulation, dealing with, use, storing and disposal. As indicated by the guidance created and utilized by the US Department of Energy (DOE 2007) [48] and the UK Environment Agency (EA) Guidance for the transfer of hazardous materials, an arrangement for storing and disposal of nanomaterials or nanomaterials contaminated waste ought to be created, taking in thought the hazardous idea of the materials and the amounts included and connected to nanomaterial-bearing waste streams (solid and fluid waste), including:

a) pure nanomaterials;

b) Items contaminated with nanomaterials, for example, holders, wipes and dispensable PPE;

c) Liquid suspensions containing nanomaterials

Figure 6 shows the various stages that the nanomaterial or nanomaterial-bearing waste could go through beginning from the production till the end of-life [49]. We have discussed in the previous sections the precautions must be taken when dealing with the production of the nanomaterials, here below is how to store the nanomaterials and how to collect and dispose the waste or the contaminated tools which are used in handling these nanomaterials.

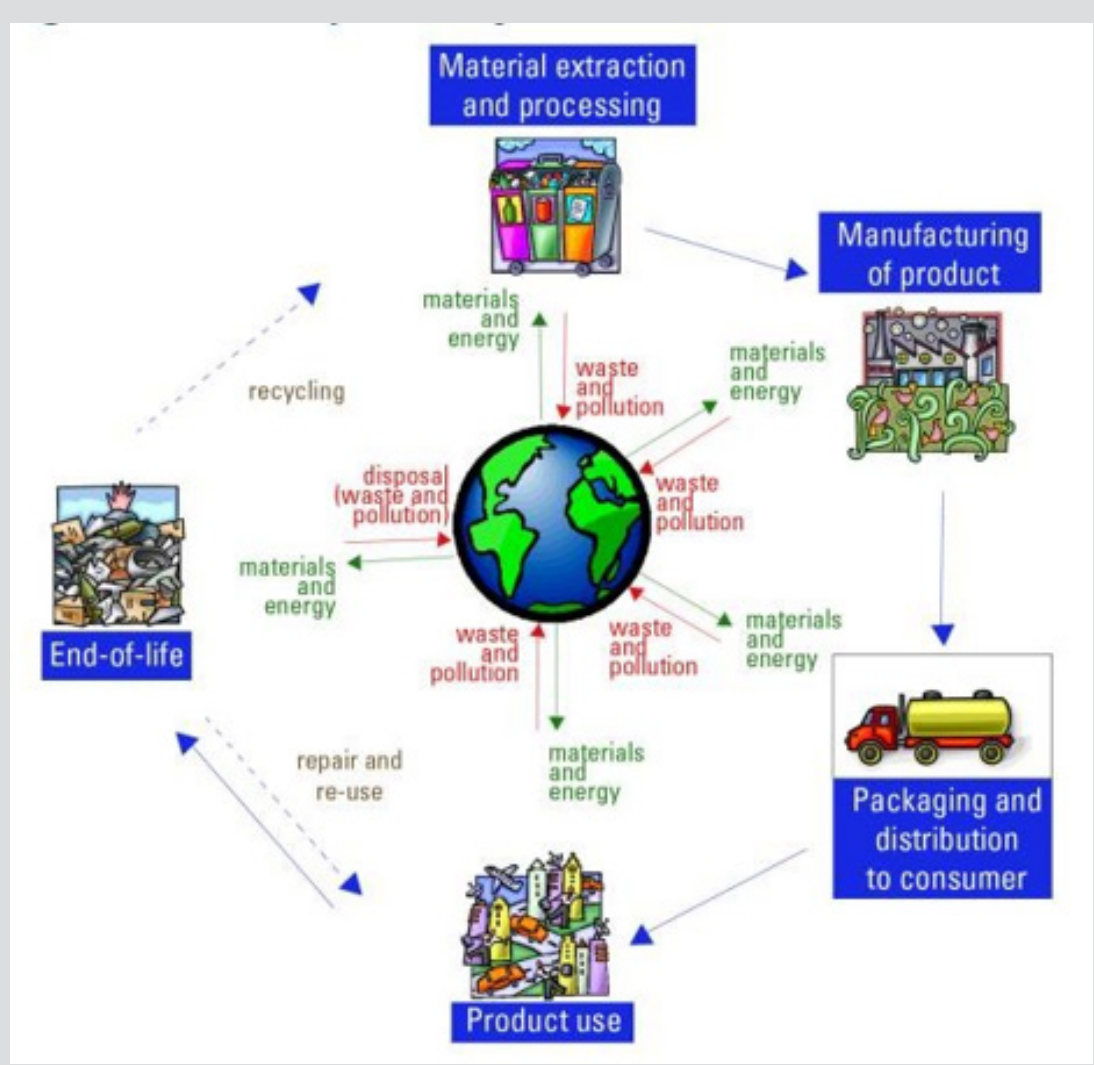

Figure 6: Life cycle perspective of the nanomaterial.

\section{Storage of Nanomaterial Waste Prior to Disposal}

Coming up next are suitable methodologies for collection and storing of nanomaterial waste before disposal:

a) Storage in Waste Container: that are in great condition to anticipate the spillage of the nanomaterials. Mark the waste com- partment with a depiction of the waste and incorporate accessible data describing known and suspected properties.

b) Storage in Plastic Packs: Collect paper, wipes, PPE and different things with free contamination in a plastic pack or other sealable compartment put away in the laboratory hood. At the point 
when the pack is full, close it and cautiously place it into another plastic sack or other fixing holder, to maintain a strategic distance from outside contamination. Remove it from the hood and name the external sack with a suitable waste mark.

\section{Disposal of Nanomaterial Waste}

It is a sensible most reasonable scenario presumption to consider all nanomaterial wastes as potentially hazardous. It can consequently be discarded as synthetic waste. The List of Waste Regulations 2005 (LOWR) [50] gives point by point data about how to deal with and discard different sorts of wastes. Two classifications are especially important: wastes from organic chemical process and wastes from inorganic chemical process. Most nanomaterial wastes can be sorted under these codes. LOWR additionally gives a rundown of hazardous properties, including models, for example,

H5: "Harmful" substances which on the off chance that they are breathed in or ingested or in the event that they infiltrate the skin may include limited health risks"- would be a sensible most pessimistic scenario presumption for many soluble and insoluble nanoparticle types-and

H6: "Toxic" substances which on the off chance that they are breathed in or ingested or in the event that they entered the skin may include acute or chronic health risks and even death"- would be a sensible most pessimistic scenario suspicion for carbon nanotubes or different nanomaterials having a fibrous nature. The guidelines indicate that the most extreme concentration for toxic substances is $3 \%$ by mass.

\section{Prevention of Fire and Explosion}

In the UK, issues of fire and explosion are secured by the Dangerous Substances and Explosive Atmospheres Regulations (DSEAR 2002) [51]. They set least requirements for the insurance of laborers from fire and explosion risks identified with hazardous substances and potentially explosive atmospheres and from gases under pressure and substances corrosive to metals and expect businesses to control the risks to the health of workers and consumers from these hazards. The effectiveness of methods for nanoparticle fire, explosion and catalysis prevention and control are yet to be evaluated. In some types of nanoparticle products dense clouds of nanoparticle powder are difficult to see, even though a suspension of the same product at the same concentration with coarser grade is easily visible. Explosion protection measures for dust dispersions and for hazardous quantities of larger sized materials can be applied to the handling of potentially explosive nanoparticles, as follows:

a) For reactive or catalytically active nanoparticles: contact with incompatible substances should be prevented [48].

b) For electrical requirements: the design of electrical equipment protection should consider the fine granulometry and very long settling time of nanoparticles, which require dust protection. Besides, further precautions should be taken to avoid the risk of auto-ignition of nanoparticles [52].

To reduce the risks of fire and deflagration, every employer shall ensure that risk is either eliminated or reduced by following measures listed below:

To reduce the risks of fire and deflagration, every employer shall ensure that risk is either eliminated or reduced by following measures listed below:

a) Reduction of the quantity of dangerous substances to a minimum

b) Control of the release of a dangerous substance at source

c) Prevention of the formation of an explosive atmosphere, including the application of appropriate ventilation

d) Ensuring that any release of a dangerous substance which may give rise to risk is suitably collected, safely contained and removed to a safe place.

e) Avoid ignition sources; ignition sources including electrostatic discharges. Anti-static shoes should be worn in areas where the materials are handled to reduce the build-up of static charge [53].

In case of fire or explosion, the selection of an extinguishing agent should take account of the compatibility or incompatibility of the nanomaterial with water. Some metallic dusts react with water to form hydrogen, which ignites very easily. Chemical powders are available to extinguish burning metallic dust powders; yet, this has the effect of putting the metallic dust in suspension, thereby increasing the risk of deflagration. Table 1 shows the chemicals that liberate flammable gas when contact with water [54].

a) Using carbon dioxide, nitrogen or another inert gas as extinguisher. Sometimes, this could introduce further hazards into the system, notably the risk of asphyxiation [55]. 
Table 1: Chemical substances that liberate flammable gases when contact with water.

\begin{tabular}{|c|c|c|c|}
\hline Substance & Risk phrase(s) & Liberated Gas & Thresold Concn \% \\
\hline Lithium & $\mathrm{R} 14 / 15$ & Hydrogen & 0.06 \\
\hline Sodium & $\mathrm{R} 14 / 15$ & Hydrogen & 0.2 \\
\hline Magnesium powder(pyrophoric) & R15-17 & Hydrogen & 0.1 \\
\hline Aluminium powder(pyrophoric) & R15-17 & Hydrogen & 0.08 \\
\hline Aluminium powder(stabilized) & R15 & Hydrogen & 0.08 \\
\hline Potassium & $\mathrm{R} 14 / 15$ & Hydrogen & 0.4 \\
\hline Calcium & R15 & Hydrogen & 0.2 \\
\hline Zinc powder/ dust(pyrophoric) & R15-17 & Hydrogen & 0.3 \\
\hline Zinc powder/dust & R15 & Hydrogen & 0.3 \\
\hline Zirconium powder(pyrophoric) & R15-17 & Hydrogen & 0.2 \\
\hline Zirconium powder(non pyrophoric) & R15 & Hydrogen & 0.2 \\
\hline Aluminium lithium hydride & R15 & Hydrogen & 0.04 \\
\hline Sodium hydride & R15 & Hydrogen & 0.1 \\
\hline Calcium hydride & R15 & Hydrogen & 0.1 \\
\hline Calcium carbide & R15 & Acetylene & 0.3 \\
\hline Calcium phosphide & $\mathrm{R} 15 / 29$ & Phosphine & 0.4 \\
\hline Aluminium phosphide & $\mathrm{R} 15 / 29$ & Phosphine & 0.3 \\
\hline Magnesium phosphide & $\mathrm{R} 15 / 29$ & Phosphine & 0.3 \\
\hline Trizinc diphosphide & $\mathrm{R} 15 / 29$ & Phosphine & 0.6 \\
\hline Trichlorosilane & R14-17 & Hydrogen & 0.6 \\
\hline Diethyl(ethyldimethylsilanato) aluminium & $\mathrm{R} 14 / 15,17$ & Ethane & 0.4 \\
\hline
\end{tabular}

\section{Regulations}

Critical discussion exists identifying with the topic of whether nanotechnology or nanotechnology-based items merit extraordinary administrative guidelines. This discussion is identified with the conditions in which it is essential and proper to survey new substances before their discharge into the market, community and environment [56]. Regulatory bodies, such as, the United States Environmental Protection Agency and the Food and Drug Administration in the U.S. or on the other hand the Health and Consumer Protection Directorate of the European Commission have begun managing the potential risks exhibited by nanoparticles. Up until this point, neither engineered nanoparticles nor the items and materials that contain them are exposed to any extraordinary regulations, with respect to production, handling of or labeling. The Material Safety Data Sheet that must be issued for certain materials regularly does not differentiate between bulk and nanoscale size of the material being referred to and notwithstanding when it does, these material safety data sheets are advisory only [57].

In The Consumer Product Safety Commission and Nanotechnology, E. Marla Felcher proposed that, the Consumer Product Safety Commission, which is accused of ensuring the general population against absurd risks of damage or passing related with consumer products, is poor-equipped for supervising the safety of high-tech products that made utilizing nanotechnology [58].

\section{Managing How to Deal with the Nanomaterial}

Now, after we reviewed the nanomaterials and how to deal with them, starting from the production and till their end-of-life, we are ready to make a plan before using any nanomaterial for each activity and for each nanomaterial to: avoid, reduce or even eliminate the hazardous impacts of these materials on both human and environment.

\section{Ranking the Nanomaterial}

Initially, it is desirable to rank the nanomaterial as per its health hazard. Three hazard classifications, 1, 2, and 3, are distinguished. The higher the classification number, the higher is the foreseen health risk. Nanoparticles of classification 1 are relatively harmless. These are required to display "just" the health hazards like the chemical mother material. Class 2 and class 3 are relied upon to display likewise explicit nano related health impacts as appeared Table 2. 
Table 2: Classification of NMP according to their possible occupational health hazards.

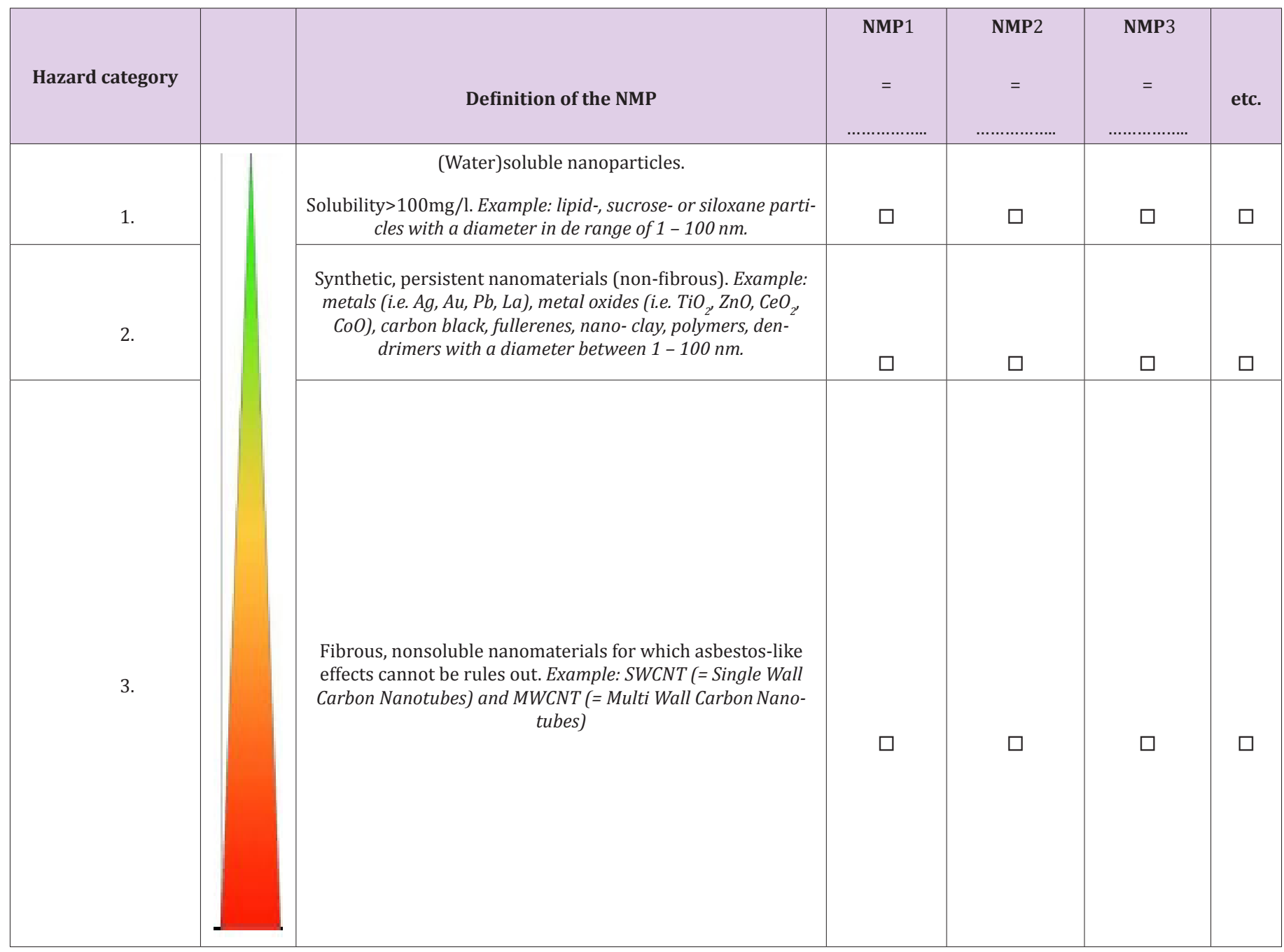

\section{Risk Management Strategy}

The health risk of dealing with NMP must be evaluated subjectively. Therefore, existing information permits organizing tem- porary risk management measures. A qualification has been made for three diverse control levels A, B and C. For each level a control approach is suggested. Table 3 offers a proposed risk the executives as per the nanomaterials health risk.

Table 3: Proposed risk management strategy according to the nanomaterial's health risk.

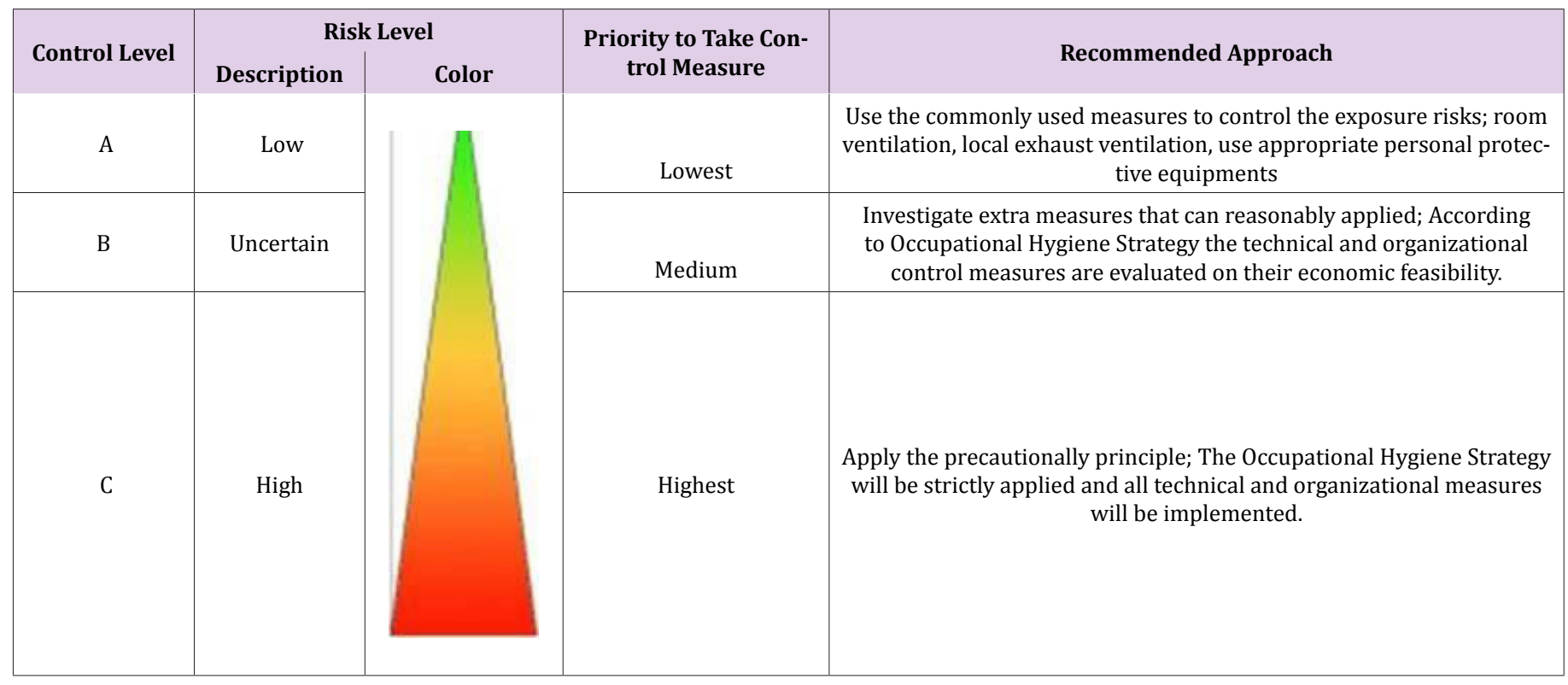


Make an Inventory of the Activities with Handling the NMP

Investigate the activities, during which nanoparticles could be discharged, this ought to be accomplished for each nanomaterial. Evaluate the entire "life cycle" of the NMP beginning from the minute the materials or items enter the organization or lab and closure when those materials or items leave the organization or lab again as "prepared for-use item" or waste material. Table 4 records ten nonexclusive exercises and distinguishes its importance for the existence period of the NMP: the essential creation of the nanomaterial (= the nano crude material generation), the auxiliary creation of the nano product (for example the creation of a nano-paint) and the expert utilization of nano products (for example the use of a nano-covering by a painter). This table could be withed to conform to any managing exercises concerning NMP.

Table 4: PCharacteristics of activities performed with NMP.

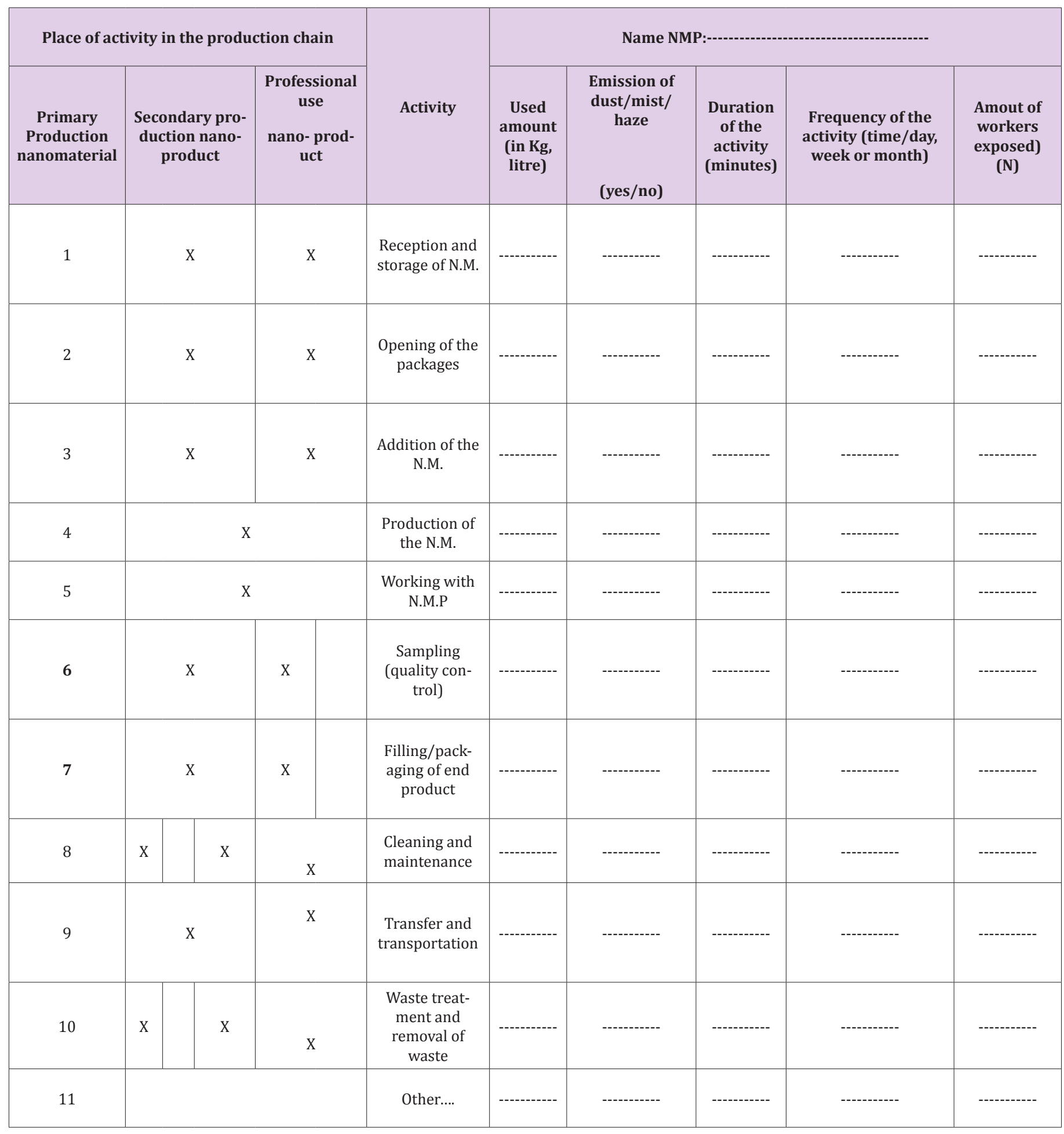


Human exposure to nanoparticles from common and anthropogenic sources has happened since ancient times. Following the innovation of burning motors and the improvement of industry, be that as it may, huge degrees of nanoparticle contamination have emerged in urban communities and even crosswise over bigger areas of our planet, with climatic and ecological impacts that are commonly obscure. There is no uncertainty that nanoparticles have interesting and valuable properties and may bring incredible advantages, however investigation into their conceivable unfriendly impacts is as yet progressing, and individuals are as of now exposed to them. Workers involved in the manufacturing of items containing nanoparticles are most at risk when not securely produced, handled, and disposed or recycled; the US National Institute for Occupational Safety and Health (NIOSH) revealed more than 2 million Americans are exposed to large amounts of these particles, and they believe this number will ascend to 4 million sooner rather than later. As appeared in this survey, obviously workers in nanotechnology related enterprises might be conceivably exposed to interestingly engineered nanomaterials. Exposure, monitoring and control techniques are vital. For sure, there is a need for another new discipline - nano toxicology - that would assess the health risks brought about by nanoparticles and would empower safe advancement of the rising nanotechnology industry.

The safety evaluation of nanoparticles and nanostructures can't depend exclusively on the toxicological profile of the proportional mass material. Nanomaterials should be assessed for their risk on a case by case for every planning including the expected utilization of the material. In completing the risk evaluation for results of nanotechnology, new testing methodologies will be necessitated that will address the item specification, the proposed use and the distinguishing proof of potential exposure situations for both human and environment. Conventional danger and ecotoxicity tests have just been demonstrated to be valuable in assessing the hazards of nanoparticles. Be that as it may, a few techniques may require alteration and some new testing strategies may likewise be required. Global participation is expected to address the various issues in nanotechnology. Institutionalization including the accessibility of reference materials/particles is the key issue to go to a shared comprehension in what we are managing as far as risk evaluation for the utilization of nanotechnology.

For nanomaterials, it is hard to set a risk appraisal appropriately because of the absence of knowledge and concurred techniques and benchmarks for testing. It has, for instance, been proposed that toxicity testing on commercially available nanomaterials would expect a very long time to finish as well as the speculation of billions US dollars.

\section{The Challenges to Comprehend the Potential Ecological} Effect of Nano Materials

The challenges to comprehend the potential ecological effect of nano materials include: a) choosing what nanomaterials represent the most noteworthy potential risks,

b) What organisms are most valuable to examine,

c) What strategies are most relevant to use, and

d) Whether conventional toxicological or emerging ecological models for surveying ecological risks are the most proper.

The present difficulties are that the accessible tools which can be utilized for surveying NMP security are frequently inappropriate, or so laborious that sufficient assessment of safety of these materials and advances remains profoundly hazardous and the assets or testing instruments are not liable to empower security evaluation of the novel nanomaterials that are flooding onto the market. This implies absolutely new safety evaluation standards should be created during the coming very long time to determine this issue. What is required is a fast identification of research needs and improvement of a guide which will slice draw a road map to guarantee the security of nanomaterials and nanotechnologies later on. Therefore, various associations need to cooperate together: from the scholarly world to health institutions, governmental organizations, independent research institutions, and independent for- profit companies. To a lesser degree, associations/organizations with unmistakable stake-holding in nanotechnology ought to partake yet not be a main thrust.

\section{References}

1. Jitendra ST, Roger AH, Hanks C, Trybula W, Fazarro D (2016) Addressing Ethical and Safety Issues of Nanotechnology in Health and Medicine in Undergraduate Engineering and Technology Curriculum. Global Journal of Engineering Education, 18(1): 30-34.

2. Rothen Rutishauser BM, Schurch S, Haenni B (2006) Interaction of Fine Particles and Nanoparticles With Red Blood Cells Visualized With Advanced Microscopic Techniques. Environmental Science \&Technology 40: 4353-4359.

3. Ueli A, Elke A, Anders B, Ken D, Bengt F, et al. (2011) Impact of Engineered Nanomaterials on Health: Considerations for Benefit-Risk Assessment, Luxembourg: European Union, EASAC Policy Report, No. 15

4. (2009) Approaches to Safe Nanotechnology Managing the Health and Safety Concerns Associated with Engineered Nanomaterials. NOISH Publication.

5. Auffan M, Rose J, Bottero J, Lowry G, Jolivet J, et al. (2009) Towards a Definition of Inorganic Nanoparticles From an Environmental, Health and Safety Perspective. Nature Nanotechnology 4: 634-641.

6. Wick P, Manser P, Spohn P, Bruinink A (2006) In Vitro Evaluation of Possible Adverse Effects of Nanosized Materials. Physica Stat Solidi 243(13): 3556-3560.

7. https://members.luxresearchinc.com/research/report/2386

8. MR Gwinn, V Vallyathan (2006) Nanoparticles: Health Effects-Pros and Cons. Environ Health Perspect 114(12): 1818-1825.

9. Buseck PR, Adachi K (2007) Nanoparticles in the Atmosphere. Elements, 4(6): 389- 394.

10. Akarslan F, Demiralay H (2015) Effects of Textile Materials Harmful to Human Health. ACTA PHYSICA POLONICA A 128: 407-408.

11. Ross BL, Aitken RJ (2011) Environmental, Health \& Safety (EHS) Impacts Technology Sector Evaluation: Textiles. Report of the Observatory NANO Project. 
12. (2011) European Academies Science Advisory Council (easac), Impact of Engineered Nanomaterials on Health: Considerations for Benefit-Risk Assessment. Joint EASAC-JRC Report, September.

13. (2010) Nanoparticle Safety and Health Guidelines, Purdue University p. $1-5$

14. Craig AP, Duffin R, Kinloch I, Maynard A, Wallace W, et al. (2008) Carbon Nanotubes Introduced Into the Abdominal Cavity of Mice Show Asbestos-Like Pathogenicity in a Pilot Study. Nature Nanotechnology 3 : 423-428.

15. Zolnik BS, González Fernández A, Sadrieh N, Dobrovolskaia MA (2010) Nanoparticles and The Immune System. Endocrinology 151: 458-465.

16. Smith MJ, Brown JM, Zamboni WC, Walker NJ (2014) From Immunotoxicity to Nanotherapy: The Effects of Nanomaterials on The Immune System. Toxicol Sci 138: 249-255.

17. Takagi A, Hirose A, Futakuchi M, Tsuda H, Kanno J (2012) DoseDependent Mesothelioma Induction by Intraperitoneal Administration of Multi-Wall Carbon Nanotubes in p53 Heterozygous Mice. Cancer Sci 103: $1440-1444$

18. (2013) Occupational Exposure to Carbon Nanotubes and Nanofibers, NIOSH Publisher.

19. (2011) Occupational Exposure to Titanium Dioxide, NIOSH Publisher. April.

20. Rossi EM, Pylkkänen L, Koivisto AJ, Vippola M, Jensen KA, et al. (2010) Airway Exposure to Silica-Coated $\mathrm{TiO}_{2}$ Nanoparticles Induces Pulmonary Neutrophilia in Mice. Toxicol Sci 113: 422-433.

21. Lindberg HK, Falck GC, Catalán J, Järventaus H, Santonen T, Norppa H (2010) Micronucleus Assay for Mouse Alveolar Type II and Clara cells. Environ Molec Mutag 51: 164-172.

22. Bihari P, Holzer M, Praetner M, Fent J, Lerchenberger M, Reichel CA, et al. (2010) Single-Walled Carbon Nanotubes Activate Platelets and Accelerate Thrombus Formation in The Microcirculation. Toxicology 269: 148-154.

23. Castranova V, Schulte PA, Zumwalde RD (2012) Occupational Nanosafety Considerations for Carbon Nanotubes and Carbon Nanofibers. Acc Chem Res 5.

24. Nymark P, Catalán J, Suhonen S, Järventaus H, Birkedal R, et al. (2012) Genotoxicity of Polyvinylpyrrolidone-Coated Silver Nanoparticles in BEAS 2B cells. Toxicology 8.

25. Chandra PR, YU H, FU P (2009) Toxicity and Environmental Risks of Nanomaterials: Challenges and Future Needs. J Environl Sci Health 27: $1-35$.

26. Gulson B, McCall M, Korsc, M, Gomez L, Casey P, et al. (2010) Small Amounts of Zinc from Zinc Oxide Particles in Sunscreens Applied Outdoors Are Absorbed through Human Skin. Toxicol Sci, 118: 140-149.

27. Monteiro Riviere NA, Inman AO, Zhang LW (2009) Limitations and Relative Utility of Screening Assays to Assess Engineered Nanoparticle Toxicity in a Human Cell line. Toxicol Appl Pharmacol 234: 222-235.

28. Vogel U, Savolainen, Wu KQ, Van Tongeren, M Brouwer D, et al. (2014) Handbook of Nano Safety: Measurement, Exposure and Toxicology. Academic Press Elsevier, London, pp 223-278.

29. Dinga Y, Kuhlbuschb TJ, Van Tongerend M, Sánchez AJ, Tuinmane I, et al. (2017) Airborne Engineered Nanomaterials in tThe WorkplaceA Review of Release and Worker Exposure During Nanomaterial Production and Handling Processes. J Hazard Mater 322: 17-28.

30. Pietroiusti A, Magrini A (2014) Engineered Nanoparticles at The Workplace: Current Knowledge About Workers' Risk". Occup Med 64(5): 319-330

31. Wickson F, Nolde Nielsen K, Quist D (2011) Nano and The Environment: Potential Risks, Real Uncertainties \& Urgent Issues. Biosafety Brief pp. $1-11$.
32. Stander L, Theodore L (2011) Environmental Implications of Nanotechnology- An Update. Int J Environ Res Public Health 8(2): 470 479

33. Han C, Andersen J, Pillai SC, Fagan R, Falaras P, et al. (2013) Green Nanotechnology: Development of Nanomaterials for Environmental and Energy Applications. ACS Symposium Series 1124: 201-229.

34. Matthew K, Robin GW, Phil M, James W, Brian W (2006) From Bio to Nano: Learning Lessons from the UK Agricultural Biotechnology Controversy. Science as Culture, Routledge, 15(4): 291-307.

35. Nowack B (2009) The Behavior and Effects of Nanoparticles in the Environment. Environmental Pollution 57: 1063-1064.

36. Asbach C (2015) Exposure Measurement at Workplaces, In: Nano Engineering: Global Approaches to Health and Safety Issues, Patricia I. Dolez, Elsevier Amsterdam pp. 523-555.

37. Gottschalk F, Nowack B, Gawlik B (2010) Report on Exposure Scenarios and Release of Nanomaterials to the Environment.

38. Buzea C, Blandino II, Robbie K (2007) Nanomaterials and Nanoparticles: Sources and Toxicity. Biointerphases, 2(4): 17-21.

39. (2010) NanoSafety- Risk Governance of Manufactured Nanoparticles Interim Report - Phase II. European Technology Assessment Group ETAG, Karlsruhe and Vienna, October.

40. Palm ET, Hansso SO (2006) The Case for Ethical Technology Assessment (eTA). Technological Forecasting \& Social Change 73: 543-558.

41. Bowman D, Fitzharris M (2007) Too Small for Concern: Public Health and Nanotechnology. Australian and New Zealand Journal of Public Health 31(4): 382-384.

42. Dunn HK, Topmiller J, Garcia A, Lo L, McCleery T (2016) Engineering Controls for Nanotechnology. NOISH, NanoTechnology Research Center.

43. (2013) Working Safely with Engineered Nanoparticles: Work Health and Safety Manual. University of South Australia pp. 1-26

44. (2008) Department of Energy Nanoscale Science Research Centers Approach to Nanomaterial ES\&H, Revision 3a, May 12: 1-28.

45.(2011) Respiratory Protection for Workers Handling Engineered Nanoparticles, NIOSH Science Blog 7.

46. (2009) Interim Guidance for Medical Screening and Hazard Surveillance for Workers Potentially Exposed to Engineered Nanoparticles, NIOSH.

47. (2013) Occupational Safety and Health administration (OSHA) Fact Sheet, U.S. Department of Labor.

48. (2007) Department of Energy Nanoscale Science Research Centers Approach to Nanomaterial ES\&H, Revision 2, June.

49. Brouwer D, Kuijpers E, Bekker C, Asbach C, Kuhlbusch TAJ (2015) Field and Laboratory Measurements Related to Occupational and Consumer Exposure In: Safety of Nanomaterials Along Their Lifecycle: Release. Exposure and Human Hazard, Taylor \& Francis.

50. (2005) The List of Wastes (England) Regulations (LOWR). Great Britain SI pp. 895.

51. (2002) Health and Safety: The Dangerous Substances and Explosive Atmospheres Regulations 2002, No. 2776.

52. ISO/TC 229 WG3 PG1 Technical Report: Health and safety practices in Occupational Settings Relevant to Nanotechnologies, in preparation.

53.(2002) The Dangerous Substances and Explosive Atmospheres Regulations, Great Britain, SI 277(6)

54. (2014) Health and Safety Guidance Hazardous Waste: Guidance on Assessment, University of Birmingham, Great Britain.

55. (2007) Nanotechnologies -Part 2: Guide to safe handling and disposal of manufactured nanomaterials, British Standards BSI 
56. HG Park, MK Yeo (2016) Review Paper: Nanomaterial Regulatory Policy for Human Health and Environment. Mol Cell Toxicol 12: 223-236

57. D Bowman, G Hodge (2007) A Small Matter of Regulation: An International Review of Nanotechnology Regulation. Columbia Science and Technology Law Review 8: 1-32.

\section{ISSN: 2574-1241}

DOI: 10.26717/BJSTR.2019.19.003346

Eman M Osman. Biomed J Sci \& Tech Res

(C) This work is licensed under Creative Commons Attribution 4.0 License

Submission Link: https://biomedres.us/submit-manuscript.php
58. D Bowman, G Hodge (2006) Nanotechnology: Mapping the Wild Regulatory Frontier. Futures 38(9): 1060-1073.

$\begin{array}{ll}\text { BIOMEDICAL } & \text { Assets of Publishing with us } \\ \text { RESEARCHES } & \text { - Global archiving of articles } \\ & \text { - Immediate, unrestricted online access } \\ & \text { - Rigorous Peer Review Process } \\ \end{array}$

